\title{
trabalnonecessário
}

issn: $1808-799 \mathrm{X}$

ano 4 - número 4 - 2006

\section{QUANDO OS PATRÕES DESTROEM MÁQUINAS \\ O DEBATE EM TORNO DAS FORÇAS PRODUTIVAS EM FÁBRICAS RECUPERADAS \\ ARGENTINAS E URUGUAIAS[1]}

Henrique Tahan NOVAES[2]

\begin{abstract}
A insistência de Gandhi na proteção dos artesanatos das aldeias não significava uma conservação estática das tecnologias tradicionais. Ao contrário, implicava o melhoramento das técnicas locais, a adaptação da tecnologia moderna ao meio ambiente e às condições da Índia, e o fomento da pesquisa científica e tecnológica, para identificar e resolver os problemas importantes imediatos. Seu objetivo final era a transformação da sociedade hindu, através de um processo de crescimento orgânico, feito a partir de dentro, e não através de uma imposição externa (HERRERA et al.,1994, p. 272)
\end{abstract}

Resumo

Title

Abstract

\section{Introdução}

Este artigo é o resultado de uma pesquisa que teve por objetivo avaliar o fenômeno das Fábricas Recuperadas (FRs) na América Latina e também de inúmeros diálogos com pesquisadores (especialmente meus orientadores Paulo Lima Filho e Renato Dagnino), outros amigos, trabalhadores, trabalhadoras e representantes dos movimentos sociais argentinos e uruguaios. $O$ projeto de pesquisa nasceu de um convênio entre a Universidade de Buenos Aires (UBA) e a Universidade Estadual de Campinas (UNICAMP) para investigar o processo de Adequação Sócio-Técnica (AST) nas FRs[3].

Antes de inserir o tema de pesquisa, optou-se por esclarecer uma interpretação de senso comum que nos parece equivocada e vem sendo disseminada tanto na Argentina como no Brasil. Para muitos teóricos apressados, o movimento luddita pode ser caracterizado como sendo um movimento primitivo, anti-progresso, inútil, que direcionava seus ataques de forma ingênua à maquinaria, e não ao sistema capitalista. Ou melhor dizendo, o senso 
comum vê um equívoco no foco da luta luddita ao quebrar máquinas quando o que se deveria questionar na verdade é o uso que se faz destas na sociedade capitalista. Para o caso das FRs, isso significaria dizer - equivocadamente - que o problema reside simplesmente em herdar as forças produtivas, posição esta que é dominante na Argentina e Uruguai, "sem promover significativas modificações na estrutura tecnológica herdada" (NOVAES e DAGNINO, 2004, p.34).

O questionamento da divisão do trabalho na empresa e a tecnologia herdada não se constituem num problema para os movimentos de FRs, tão pouco para academia argentina e uruguaia. Centrando a maior parte do debate nas possibilidades da democracia direta - uma vez que nas FRs cada sócio representa um voto - estes pesquisadores sofrem do mesmo mal brasileiro ao não problematizar a imprescindível necessidade de reprojetamento das máquinas e instalações herdadas assim como a necessidade de criação de uma nova divisão de trabalho. Numa palavra, não está em debate a necessidade de novas forças produtivas, socialistas.

A escolha do movimento luddita como pano de fundo não se deu por acaso. Além de verificarmos uma visão muito simplista quando se aborda este movimento, o caso argentino ilustra um fato curioso: muitos patrões atuaram neste país como ludditas às avessas ao sabotarem a produção com o intuito explícito de impedir ou retardar o controle operário (HELLER, 2004; KLEIN apud MAGNANI, 2003)[4].

Depois de apresentar brevemente a interpretação que nos parece ser a mais correta do movimento luddita, o artigo contextualiza o surgimento das FRs argentinas para depois abordar as intervenções dos patrões para bloquear o processo de autogestão.

Em seguida, são expostos alguns processos de AST encontrados na Argentina e Uruguai. Buscamos avaliar em que medida a mudança de propriedade está levando a uma nova configuração sócio-técnica ou ainda como a mudança do "grupo social relevante" (BIJKER, 1995) que inside sobre a tecnologia pode levar a diferentes processos de AST. Isso não significa dizer que os trabalhadores não modificavam o processo de produção antes da falência das fábricas (NOVAES, ASSIS e DAGNINO, 2004), mas que agora eles têm possibilidades privilegiadas de intervir no espaço de trabalho (HOLZMANN, 2000).

\section{Os Destruidores de Máquinas}

Hobsbawm (1981), em Os destruidores de máquinas, aponta que os equívocos a respeito do sindicalismo, do operariado e sobre a maquinaria advém da interpretação incorreta de Webbs e seus seguidores fabianos: "As opiniões conscientes da maioria dos estudiosos podem ser resumidas como se segue: o triunfo da mecanização era inevitável”. O luddismo foi descrito por alguns simplesmente como uma Jaquerie[5] Industrial sem propósito e frenética. Outra autoridade do assunto os descreve com a sugestão de que os ludditas eram o transbordamento da excitação e da animação (HOBSBAWM, 1981, p.22).

O mérito do artigo constitui-se em desmistificar a reação da classe trabalhadora como 
sendo unicamente em torno do avanço da maquinaria. Para este autor, "a destruição era simplesmente uma técnica do sindicalismo no período anterior e durante as primeiras fases da revolução industrial" (HOBSBAWM, 1981, p.22).

Dentre os vários tipos de quebras de máquinas, pode-se destacar que os trabalhadores de Debyshire usaram os ataques contra as máquinas, velhas ou novas, como meio de forçar seus empregadores a fazer-Ihes concessões salariais. Em Devon, tecelões ameaçavam queimar e demolir as casas de negociantes de tecidos a menos que estes concordassem com suas condições. Já a luta de mineiros, através de destruição e insurreições se davam em torno dos altos preços dos alimentos.

As destruições e insurreições eram utilizadas quando os salários ou as condições de vida da classe trabalhadora mudavam subitamente e também como forma de greve por um tempo mais longo, isso porque o equipamento quebrado era garantia de que as máquinas não funcionariam temporariamente (HOBSBAWM, 1981).

Outra variante da destruição advém da hostilidade da classe trabalhadora às novas máquinas, especialmente as que economizavam mão de obra. Hobsbawm (1981) adverte que o trabalhador não estava preocupado com o progresso técnico abstratamente mas sim com o problema prático do desemprego e do padrão de vida. O objetivo supremo da classe trabalhadora consistia em regular o mercado de trabalho (quebrar máquinas que economizava mão de obra) e evitar os furos das greves.

O exemplo clássico é o de tecelões de Spitafields, onde trabalhadores insurgiram-se contra as máquinas pelas quais "um homem pode produzir tanto como quase vinte sem elas" (HOBSBAWM, 1981, p.27).

Entre homens e mulheres mal pagos, sem fundos de greve, o perigo de furadores de greve é sempre agudo. A quebra de máquinas foi um dos métodos de contra atacar essas fraquezas. A vantagem do equipamento quebrado é a garantia de que a máquina não funcionaria temporariamente. De acordo com Geoffrey Bernstein (apud NOBLE, 2000), quebrar máquinas servia para mobilizar pessoas com diferentes preocupações imediatas em regiões geográficas distintas, integradas em sindicatos diferentes, dando coerência ao movimento, estimulando lealdades e dando aos trabalhadores um sentido de solidariedade.

No entanto, quando a mudança técnica não trazia nenhuma desvantagem aos trabalhadores, não se encontra nenhuma hostilidade contra as máquinas: no caso de tipógrafos, "a adoção de prensas movidas a motor parece haver causado pouca perturbação" (HOBSBAWM, 1981, p.28).

Hobsbawm ressalta que a hostilidade às máquinas poupadoras de mão de obra não era tão indiscriminada nem tão específica como se tem presumido muitas vezes. Com exceções locais ou regionais, ela foi surpreendentemente fraca na prática[6]. Ela não se restringiu aos trabalhadores, mas foi partilhada pela grande massa da opinião pública, inclusive industrialistas médios.

Nesta época, os empresários capitalistas de grande porte formavam uma pequena minoria. 
O pequeno lojista ou o patrão local não queria uma economia de expansão ilimitada, acumulação e revolução técnica, a selvagem briga de foice que condenava os fracos à falência e ao status de assalariado. Seu ideal era o sonho secular de todos os "pequenos homens", uma sociedade em pequena escala de proprietários modestos e assalariados em condições confortáveis. Mas se o empresário inovador tinha o grosso da opinião pública contra ele, como ele conseguiu se impor? Obviamente por meio do Estado. De acordo com Hobsbawm (1981) a Revolução burguesa de 1640-60 na Inglaterra marca o momento decisivo na atitude do Estado em relação à maquinaria.

Deve-se lembrar ainda que a maioria das máquinas tendia a ser introduzida em ocasiões de prosperidade crescente, quando o nível de empregos estava melhorando e a oposição, não totalmente mobilizada, podia ser dissipada por algum tempo (HOBSBAWM, 1981). Numa parte que nos interessa muito, o historiador 'inglês' afirma que "é verdade que em muitas indústrias o objetivo de impedir a introdução de máquinas indesejáveis havia cedido lugar, com o advento da mecanização completa, ao plano de 'capturá-las' para os trabalhadores que gozavam de padrões e condições sindicais" (HOBSBAWM, 1981, p.22). Podem então o tumulto e a quebra de máquinas deter o avanço do progresso técnico? Hobsbawm responde que "potentemente não podem deter o triunfalismo do capitalismo industrial como um todo. Numa escala menor, no entanto, eles não são de maneira alguma a arma desesperadamente ineficiente que se tem feito parecer" (HOBSBAWM, 1981, p. 27). O luddismo dos tosquiadores de Wiltshire em 1802 certamente adiou a generalização da mecanização. E encerra observando:

Quanto desse sucesso foi devido aos homens, quanto ao luddismo latente ou passivo dos próprios empregadores, não podemos, contudo, determinar. No entanto, qualquer que seja a verdade na questão, a iniciativa veio dos homens, e até esse ponto eles podem reivindicar uma parcela importante em qualquer desses sucessos (HOBSBAWM, 1981, p. 27).

Buscando desmistificar a tecnologia como sendo autônoma, livre das influências da política e da sociedade, e trazer a construção tecnológica para o campo da luta concreta, Noble (2000) retrata no Livro Una visión diferente del progreso- en defensa del luddismo a percepção daqueles que estão no "centro de produção", para deste modo mostrar as respostas do passado e incitar as respostas no "presente" sobre uma tecnologia aparentemente incontrolável e inevitável: "La gente en el centro de producción fue la primera que comprendió el significado integral del devastador ataque de la Revolución Industrial - no por medio de una superior sofisticación dialéctica, sino a causa de lo que ya suponía para sus vidas - y respondieron consecuentemente" (NOBLE, 2000, p.9).

Enquanto os escritos da época eram formulados tendo em vista a derrubada da visão daqueles que lutavam pela sobrevivência e contra os supostos progressos da Revolução Industrial, Noble acredita que os ludditas não se confundiam com esta invenção ideológica. Eles não tinham fé no progresso tecnológico, nem podiam crer, pois se tratava de uma idéia estranha a eles que foi inventada posteriormente para prevenir a reaparição de 
movimentos tal como este.

Dentro desta invenção ideológica, os ludditas foram então chamados de contra o progresso, primitivos, provincianos, inúteis. Para Noble, os Ludditas foram "os únicos que perceberam a tecnologia no presente concreto e que atuaram conseqüentemente, destruíram máquinas". Citando Maxine Berg, Noble (2000) observa que "a máquina não era uma conquista, mas o resultado de uma imposição" (NOBLE, 2000, p.10).

Noble comenta que muitas interpretações revisionistas mostram os ludditas não lutando contra a tecnologia per se, mas também contra as mudanças sociais que a nova tecnologia produzia e consolidava. Uma argumentação por esta via diria que os ludditas lutavam contra os esforços do capital, pois este utilizava a tecnologia para reestruturar as relações sociais.

Desta maneira, os trabalhadores da Primeira Revolução Industrial estavam reagindo contra a entrada das relações sociais capitalistas, marcadas pela criação de um sistema de dominação que implicava em sua ruína ou na "escravidão assalariada", e eram plenamente conscientes de que a introdução das novas tecnologias pelos seus inimigos fazia parte de um esforço capitalista tendo em vista a arruinação deles: "não tinham nada contra a maquinaria, mas também não tinham um respeito excessivo por elas. Na hora da escolha (...) entre as máquinas do capitalista e suas próprias vidas, não tinham muitos problemas em escolher o que era mais importante" (NOBLE, 2000, p.12)[7]. É impressionante observar que a rapidez da mudança tecnológica, que é em si mesma desestabilizadora e que tem sido utilizada reiteradas vezes para colocar o trabalhador na defensiva, não era percebida naquele tempo como inevitável (BERG apud NOBLE, 2000).

\section{Breve histórico argentino e o contexto no fim do século XX}

Desde a ditadura militar, a indústria argentina vem sendo destruída, enterrando qualquer possibilidade de um novo desenvolvimento glorioso na periferia - o capitalismo com inclusão social, como dizem alguns. Aquilo que aparece nos jornais portenhos como sendo uma crise violenta, porém conjuntural, é vista por outros como uma crise estrutural do capital, que abrange não só a periferia mas também o centro do capitalismo (LIMA FILHO, 2002)[8].

É neste contexto de crise estrutural que surge na Argentina os piqueteiros, as assembléias de bairro, os ahorristas damnificados, os clubes de troca e as FRs[9].

No entanto, faz necessária uma advertência. Mesmo sabendo que o objetivo primordial das FRs seja a defesa dos postos de trabalho, elas não são uma resposta automática as condições macroeconômicas dos anos 1990, mas também o resultado de um novo contexto, de um novo clima político social e de uma "crise estrutural do capital" (HELLER, 2004). Na Argentina, as FRs surgem como "cooperativas de necessidade"[10], empresas de porte mediano e pequeno que surgem de um processo de encolhimento[11] e esvaziamento das fábricas ocorrido no fim dos anos 1990 e início do século (FAJN et al., 
2003, p. 65).

Mais precisamente, trata-se de um novo fenômeno social ou num novo método desenvolvido pelas classes trabalhadoras brasileira, argentina, uruguaia que é o resultado de uma mistura de clima social e uma saída para trabalhadores que não encontravam mais na luta sindical tradicional uma saída para sua reprodução social (MURUA, 2004)[12].

Frente a isso, muitos trabalhadores optaram por ocupar fábricas, reivindicar a expropriação definitiva dos meios de produção, repartição igualitária do excedente e instalação de mecanismos de decisão parlamentarista no seio da unidade produtiva. Não podemos esquecer que o ato de recuperar a fábrica significa para o trabalhador recuperar algo no qual ele se sente participante, que ajudou a construir, que faz parte da sua história de vida.

Não é preciso dizer que muitos trabalhadores viveram um grande período de escravização durante o processo anterior à falência. Verificou-se através do relato de trabalhadores que eles apenas recebiam o dinheiro para o passe de ônibus durante meses, sem qualquer perspectiva de ver seu salário de volta.

Um problema que apareceu à academia como essencialmente defensivo, sendo o resultado de uma crise avassaladora do desemprego, desvela uma realidade e nos leva a pensar nas FRs como sendo um fato histórico que enseja um olhar muito mais amplo do que uma simples questão de emprego, nos levando a pensar no tema da alienação do trabalho (BIALAKOWSKY, 2003; NOVAES, 2005b).

\section{Os ludditas às avessas: quando os patrões destroem máquinas}

Um fenômeno curioso aconteceu na Argentina no fim do século XX. Se no século XIX a quebra de máquinas pelos trabalhadores era uma das táticas para interromper a produção por um tempo -conforme vimos na primeira seção-, na Argentina se dá o contrário. Muitos patrões, com o intuito de impedir que as fábricas fossem controladas pelos trabalhadores, iniciaram processos de esvaziamento da empresa, seja através da retirada de peças e equipamentos centrais ao bom funcionamento da produção, seja por uma crise induzida ou criação de empresas fantasma para fraudar a quebra.

Poderíamos citar inúmeros exemplos, no entanto, nos deteremos apenas em dois. Na fábrica têxtil Brukman, fábrica essa que alcançou visibilidade internacional, os trabalhadores, após conseguir a expropriação dos meios de produção, "encontraram tierra arrasada: las máquinas estavan destruidas, las piezas mas importantes y caras de la compudadora de diseño habian sido robadas. Las calderas, el sistema elétrico, las tuberías de aire comprimido, todo estaba roto" (HELLER, 2004, p.187).

$\mathrm{Na}$ Sasetru, foram aniquiladas e desperdiçadas muitas horas de trabalho humano, dispendidos durante quase dois meses de trabalho por trabalhadores desocupados. Houve destroços, saqueamento de peças pelos patrões e sabotagem (HELLER, 2004, p. 177). O roubo foi feito pelo "pessoal altamente qualificado", que desmontou de maneira "impecável" 
os cabeçais das linhas de produção (HELLER, 2004, p.178). O objetivo principal era impedir ou ao menos fazer retardar a gestão operária (HELLER, 2004, p.178)[13].

Para impedir que as empresas fossem completamente saqueadas pelos patrões, muitos trabalhadores optaram pela tática do acampamento em frente a fábrica ou até mesmo por dormir no recinto fabril, tornando-se guardiões dos meios de produção[14].

Mesmo sabendo que tivemos no Brasil algumas ocupações e lutas extremamente fervorosas, tudo leva a crer que na nação tupiniquim houve um processo maior de negociação no qual não foi necessário recorrer ao acampamento ou ocupação das fábricas, diferentemente da Argentina, onde o processo de recuperação das fábricas está caracterizado por uma maior intensidade do conflito entre trabalhadores e patrões.

Supomos ainda que a proposta de repartição igualitária das retiradas ecoou com muito mais força na Argentina que no Brasil como resultado dessas "medidas de força" para adquirir a propriedade das fábricas e também porque as fábricas são menores. No estudo de Fajn et al. (2003) que abrange $87 \mathrm{FRs}$, nota-se que $46 \%$ das fábricas tiveram que recorrer a "tomada da fábrica" enquanto que $24 \%$ recorreram a outras "medidas de força" para recuperar a empresa (acampamento ou interrupção de trajetos de ruas) (FAJN et al., 2003, p. 40-1). Não é preciso lembrar que este método tem uma semelhança reconhecida por alguns e ignorada por outros - com o método dos acampamentos do Movimento dos Trabalhadores Sem Terra (MST) (KLEIN, 2003).

O estudo de Fajn et al. (2003) confirma a hipótese de que as fábricas que tiveram uma maior intensidade de conflito geraram laços muito estreitos entre os trabalhadores, fator esse que levou a uma solidariedade na repartição dos salários.

Isso não significa dizer que muitos trabalhadores não queiram retornar ao antigo sistema de faixas salariais. Para muitos casos, a repartição igualitária das retiradas apresenta-se como uma opção transitória frente a impossibilidade de manutenção dos antigos salários. Uma hipótese a ser verificada é se, com o bom andamento financeiro, não teremos uma volta às antigas divisões de salários.

\section{Adequação Sócio-Técnica na Argentina e Uruguai}

As demandas de participação e controle pelos trabalhadores escapam de muito à visão marxista. O conceito de uma democracia na oficina baseada simplesmente na imposição de uma estrutura formal de parlamentarismo - eleição de diretores, votação sobre decisões referentes à produção - de acordo com a organização existente, é decepcionante. Sem o retorno do requisito de conhecimento técnico pela massa dos trabalhadores e reformulação da organização do trabalho - sem, em uma palavra - um novo e verdadeiramente coletivo modo de produção - a votação nas fábricas e escritórios não altera o fato de que trabalhadores continuem dependendo tanto quanto antes dos 'peritos' e só podem escolher entre eles ou votar nas alternativas apresentadas por eles (BRAVERMAN, 1987, p.237). 
Segundo Bijker, Hughes e Pinch, Construção Sócio-técnica é o processo mediante o qual artefatos tecnológicos vão tendo suas características definidas através de uma negociação entre "grupos sociais relevantes", com preferências e interesses diferentes, no qual critérios de natureza distinta, inclusive técnicos, vão sendo empregados até chegar a uma situação de "estabilização" e "fechamento" (BIJKER, 1995, p.12).

Nesse sentido, o conceito de Adequação Sócio-técnica (AST) aqui proposto poderia ser entendido como um processo inverso ao da construção, em que um artefato tecnológico ou uma tecnologia sofreria um processo de adequação aos interesses de grupos sociais relevantes distintos daqueles que o originaram.

Uma das virtudes do conceito de AST é observar que o problema das FRs é muito mais complexo do que $o$ ato de herdar ou apropriar-se das forças produtivas. Nesse sentido, foram elaboradas modalidades de AST que pretendem retratar diferentes níveis de complexidade que as cooperativas populares e FRs podem estar alcançando.

\section{As modalidades de Adequação Sócio-Técnica}

1)Uso: $O$ simples uso da tecnologia (máquinas, equipamentos, formas de organização do processo de trabalho, etc) antes empregada (no caso de cooperativas que sucederam a empresas falidas), ou a adoção de tecnologia convencional, com a condição de que se altere a forma como se reparte o excedente gerado, é percebida como suficiente.

2)Apropriação: entendida como um processo que tem como condição a propriedade coletiva dos meios de produção (máquinas, equipamentos) ela implica em uma ampliação do conhecimento, por parte do trabalhador, dos aspectos produtivos (fases de produção, cadeia produtiva, etc), gerenciais e de concepção dos produtos e processos, sem que exista qualquer modificação no uso concreto que deles se faz.

3)Ajuste do processo de trabalho: implica a adaptação da organização do processo de trabalho à forma de propriedade coletiva dos meios de produção (pré-existentes ou convencionais), o questionamento da divisão técnica do trabalho e a adoção progressiva do controle operário (autogestão).

4)Alternativas tecnológicas: implica a percepção de que as modalidades anteriores, inclusive a do Ajuste do processo de trabalho, não são suficientes para dar conta das demandas por AST dos empreendimentos autogestionários, sendo necessário o emprego de tecnologias alternativas à convencional. A atividade decorrente desta modalidade é a busca e seleção de tecnologias existentes.

5)Incorporação de conhecimento científico-tecnológico existente: resulta do esgotamento do processo sistemático de busca de tecnologias alternativas e na percepção de que é necessária a incorporação à produção de conhecimento científico-tecnológico existente (intangível, não embutido nos meios de produção), ou o desenvolvimento, a partir dele, de novos processos produtivos ou meios de produção, para satisfazer as demandas por AST. Atividades associadas a esta modalidade são processos de inovação de tipo incremental, isolados ou em conjunto com centros de P\&D ou universidades.

6)Revitalização ou Repotenciamento das máquinas e equipamentos: significa não só o aumento da vida útil das máquinas e equipamentos, mas também ajustes, recondicionamento e a revitalização do maquinário. Supõe ainda a fertilização das 
tecnologias antigas com componentes novos.

7)Incorporação de conhecimento científico-tecnológico novo: resulta do esgotamento do processo de inovação incremental em função da inexistência de conhecimento suscetível de ser incorporado a processos ou meios de produção para atender às demandas por AST. Atividades associadas a esta modalidade são processos de inovação de tipo radical que tendem a demandar o concurso de centros de P\&D ou universidades e que implicam na exploração da fronteira do conhecimento.

\section{O olhar argentino}

A mirada argentina - e porque não a uruguaia - está reduzindo o debate sobre AST à necessidade de criação de um parlamentarismo interno a fábrica, ignorando os condicionantes relativos à tecnologia capitalista herdada (hardware, software e orgware).

Não se trata apenas de criar uma nova cultura do trabalho, como pregam alguns, mas de levar a cabo uma total reestruturação dos meios e da organização da produção, onde os trabalhadores não estejam submetidos às decisões apontadas pelos engenheiros, como nos aponta Braverman (1987) no início desta seção e Varsavsky (1974) no livro Estilos Tecnológicos. De acordo com Varsavsky (1974, p.74), ao longo do surgimento do capitalismo, o trabalhador perdeu o controle (alienou-se) dos meios de produção e "a propriedade do domínio técnico sobre a máquina que usa, e isso não se repara com decretos. Mesmo quando a fábrica é de propriedade cooperativa direta dos trabalhadores, a alienação dos mesmos não se elimina se seguem dependendo dos especialistas na mesma medida que hoje".

Nesse sentido, o conceito de AST nos obriga a pensar as FRs para além de uma simples mudança jurídica de propriedade, isso porque a alienação não se extingue através de decreto ou com uma modificação da propriedade jurídica, mas requer um longo prazo de maturação[15].

Contudo, ressaltemos inicialmente que o fato dos trabalhadores administrarem uma fábrica por si sós já é uma grande inovação (BIALAKOWSKY, 2003). Trabalhadores que antes não tinham uma vaga intuição dos aspectos relacionados a administração agora podem debater problemas relacionados a comercialização do produto, planos de investimento, maior liberdade para discutir aspectos relacionados a inovação em produtos, processos, adaptação e fertilização do antigo maquinário com componentes novos. Resta saber se as assembléias têm apenas um conteúdo informativo ou se os trabalhadores decidem com conhecimento de causa.

No entanto, tudo leva a crer que o problema é muito mais complexo do que a criação de assembléias democráticas, conselhos administrativos ou até mesmo uma nova e (e desejada) divisão do trabalho. As modalidades 6 e 7, apresentadas nas linhas acima, 
anunciam a necessidade de uma mudança radical na rota de pesquisa tecnocientífica, algo que não vem sendo pensado e muito menos feito pelos pesquisadores latino-americanos.

Supondo, por exemplo, que todas as Fábricas e Universidades estivessem falidas e sendo apropriadas pelos trabalhadores dentro de um projeto emancipatório: é bem provável que haveria de se fazer uma transformação muito mais radical, para além da apropriação dos meios de produção (NOVAES, 2005c), do que a imaginada atualmente.

Isso porque as forças produtivas: a Ciência, a Tecnologia, os meios de produção, o conhecimento parcial dos trabalhadores, as escolas e universidades dificilmente podem ser aproveitados pelos trabalhadores sem uma significativa modificação (DAGNINO, 2005; MÉSZÁROS, 2002).

É verdade que muitas das FRs vêm permitindo tanto a manutenção quanto a ampliação do conhecimento dos trabalhadores na medida em que muitos trabalhadores que antes não dialogavam ou viam no outro uma espécie de ameaça ao seu trabalho, agora são obrigados a enfrentar uma situação extremamente nova. Sabendo que o bom andamento do negócio depende do pleno comprometimento dos trabalhadores aos problemas fabris, muitos trabalhadores - vagarosamente - começam a sentir-se mais comprometidos com as questões fabris essenciais[16].

As FRs, tanto as brasileiras como as argentinas e uruguaias, também estão permitindo despercebidamente um aumento substancial da vida útil de muitas máquinas, equipamentos e instalações, que na falta dos movimentos de FRs dos dois países, seguramente iriam parar num ferro velho ou serem vendidas a um preço irrisório. No entanto, esta questão ambiental não é o resultado de um projeto preservacionista dos trabalhadores, mas sim um método de luta para salvar seus postos de trabalho, pondo a produção em marcha novamente.

Uma questão em aberto refere-se ao grau de intervenção dos partidos políticos e dos movimentos de FRs junto às mesmas. Para um observador brasileiro, o fato de algumas fábricas argentinas ter os quadros administrativos alocados externamente compromete o bom andamento da autogestão, sendo a Fábrica muito mais uma extensão do movimento do que uma entidade com vida própria.

\section{Notas sobre as Fábricas Recuperadas argentinas e uruguaias}

Comecemos pela Indústria Metalúrgica Plástica Argentina (IMPA), uma antiga fábrica do Estado processadora de alumínio que tornou-se uma "cooperativa tradicional" nos anos 60, entrou em falência nos anos 90 e se tornou uma FR. Aquilo que para muitos engenheiros e economistas era algo "inviável", por contar com uma tecnologia "defasada" 
e "obsoleta", vem não só mantendo os postos de trabalho como também gerando pequenas inovações. A cooperativa IMPA, que começou com 40 trabalhadores hoje tem 174, desenvolveu seu próprio sistema de reciclagem de alumínio quando se viram impossibilitados de comprar quantidades pequenas de aço a um preço razoável da ALUAR, antiga fornecedora de alumínio: "Estes trabalhadores tiveram que testar uma alternativa que os engenheiros haviam descartado frente a todas as sugestões, reciclar alumínio. Depois de alguns testes eles obtiveram um material que superou perfeitamente 0 controle de qualidade das peças anteriores" (MAGNANI, 2003, p.87).

Uma das fábricas mais interessantes de se analisar é a Cerâmica Zanon. Situada na província de Neuquen, esta fábrica - que atualmente está completamente "ilegal" do ponto de vista jurídico - desenvolveu uma nova linha de cerâmicos, os "cerâmicos mapuche". No entanto, há de se ressaltar que muitos trabalhadores foram enviados a Bologna justamente para isso, quando ainda esta empresa ainda era propriedade do senhor Zanon. Eles dizem que sabiam como fazer o tijolo, mas não os orçamentos de produção: "éramos trabalhadores que não sabíamos dirigir uma fábrica em termos econômicos" (MAGNANI, 2003, p.148)

Os trabalhadores reconhecem que estão completamente ilegais do ponto de vista jurídico, mas dizem: "temos que sobreviver, há uma razão social em primeiro lugar". Com um forte apelo aos vínculos da fábrica "a serviço da comunidade", continuam: "Soy un trabajador y quiero reportarle a la communidad tudo o que ella nos dio. (...) Las ganancias de esta fábrica tiene que ir para ellos" (MAGNANI, 2003, p.143)[17].

No ano de 2002, eles assinaram um convênio com a Universidade de Las Madres que permitiu superar obstáculos que estavam tropeçando em matéria de comercialização (MAGNANI, 2003).

Esta fábrica vem obtendo muitos excedentes, a ponto dos trabalhadores incorporarem a função de Fábrica-Estado. Dentre seus desejos, querem construir hospitais, escolas, aumentar a doação de cerâmica pro povo da cidade e inúmeras outras coisas. Todos os trabalhadores recebem a mesma retirada e justificam: "Eu particularmente não aceito que haja escala salarial porque significa discriminar" e que "a igual trabalho igual salário" (MAGNANI, 2003, p.145-6)[18].

Uma das maiores inovações na Argentina e no Uruguai refere-se à repartição igualitária dos "salários"[19]. No entanto, para aqueles que crêem que autogestão significa salários iguais ou crescentes, lembremos que "um possível aumento de salários somente iria melhorar a remuneração dos escravos, mas não restituiria o significado e o valor humanos nem ao trabalhador nem ao trabalho" (MARX, 1994, p. 32)[20]. 
Aqui, cabe observar, por exemplo, que a Fábrica Constituyentes (produção de canos com costura), vislumbra a manutenção da repartição igualitária das retiradas (nome que se dá ao salário em cooperativas) enquanto que a Fábrica Uruguaia Coopdi (produção de ternos) postula claramente um retorno às antigas faixas salariais quando a empresa voltar a crescer. Uma outra fábrica, que possui faixas de retirada, vislumbra construir uma repartição igualitária.

Nesse sentido, caberá avaliar ao longo do tempo se a proposta de igualação das retiradas se mantém ao longo da vida das FRs, ou é algo momentâneo, fruto de uma crise avassaladora no mercado de trabalho.

Outra comparação importante se dá entre a Fábrica Constituyentes e a Fábrica uruguaia co-gestionária Funsa (produção de pneus e luvas). Se em Constituyentes a fábrica anda muito bem sem os engenheiros, capatazes e supervisores, na fábrica Funsa, os trabalhadores disseram que é impossível tocar a produção sem o corpo de engenheiros, muitas vezes contratados como consultores[21]. Na Fábrica Constituyentes, os operários afirmam a todo momento que conseguem e conseguirão levar o projeto autogestionário adiante porque acumularam elevados graus de conhecimento empírico. Dizem que não precisam mais de engenheiros e capatazes, pois a única função destes era controlar o trabalho de planta.

Isso nos leva a pensar novamente que Braverman e Varsavsky estavam corretos ao dizer que não há cooperativismo sem uma real emancipação dos trabalhadores em relação aos engenheiros.

Os trabalhadores relatam um aumento da criatividade, o florescimento da inventividade, a estabilidade no emprego e um trabalho mais tranqüilo. Para aqueles que crêem que o capital expropriou totalmente o conhecimento dos trabalhadores, tornando-os totalmente desqualificados, as FRs são provas de que estes ainda retêm muito conhecimento, na falta disso, como estariam funcionando a maioria das fábricas argentinas que trabalham sem os quadros hierárquicos?

Na fábrica de tratores Pauny (ex Zanello), de forma parecida à Fábrica Funsa, os trabalhadores não viram outra alternativa senão a fundação de uma S/A na qual a cooperativa de trabalhadores, os gerentes e o sindicato tinha 33\% do capital cada um, restando $1 \%$ para o município (CAFFARATTI, 2004). Mesmo constatando uma reconfiguração das relações de gestão a partir da recuperação da empresa, a pesquisa de Caffaratti adverte que não houve uma mudança na organização do processo produtivo.

Destaca-se nesta cooperativa o desenvolvimento de dois produtos novos, o trator amarelo (que ganhou o prêmio de inovação tecnológica na Feira de Palermo 2003), 
movido a gás liquefeito, que permite baixar os custos de produção e não emite gases contaminantes. A outra inovação refere-se ao mini-ônibus urbano e outros automóveis que Ihes permitirá diversificar a produção (CAFFARATTI, 2004).

Na Cooperativa Union y Fuerza, o salário dobrou e todos ganham o mesmo. Relatando a mudança de postura dos seus colegas, um trabalhador diz que: se uma máquina se rompia, chamava o engenheiro e se sentava. Agora, chama os companheiros de manutenção e resolvem o problema juntos (MAGNANI, 2003, p.164). Os operários que lutaram pela reabilitação da fábrica estão diante de um problema, pois incorporarão 30 trabalhadores em fase de teste. Eles querem passar juridicamente de cooperativa de trabalho para cooperativa de produção, pois uma cooperativa de produção na Argentina tem a possibilidade de contratar pessoas e não só incorporar sócios.

A justificativa para a incorporação destes novos trabalhadores como sócios- mas com diferença acionária - se dá em função dos "6 meses de luta, e os 3 anos para atingir este (atual) nível de produção" (MAGNANI, 2003), o que para eles não é justo.

Um outro problema que entrava significativamente as FRs argentinas e uruguaias é a quantidade de empresas que trabalham "à façon". Em linhas gerais, trabalho a façon quer dizer que o demandante fornece todo o material e apenas contrata as cooperativas para elaborar o produto desejado. Não há qualquer margem de manobra frente às imposições de preço e compra dos produtos[22].

Dentre os riscos organizacionais iminentes a autogestão, Fajn et al. (2003) destaca a conformação de um segmento burocrático que se aproprie dos saberes de gestão, substituindo os donos por um novo estamento burocrático que concentra a informação, o saber da gestão e o conjunto de decisões estratégicas da organização. Um outro risco refere-se à impossibilidade de desestruturar a hierarquização operada pela relação capitaltrabalho e conservar tanto no âmbito da estrutura organizacional como no atinente ao processo de trabalho às formas herdadas antes da recuperação.

Nesse sentido, a divisão do trabalho, as hierarquias internas, a classificação remunerativa, a atribuição de funções, tarefas e responsabilidades são um conjunto de lógicas organizacionais instituídas que requerem ser revisadas e reformuladas sobre as perspectiva e parâmetros do novo projeto coletivo (FAJN et al., 2003, p. 147-8).

A não percepção dos riscos que o maquinário de última geração pode trazer aos princípios da autogestão deve ser também considerada como um problema. Em muitos diálogos com professores e trabalhadores, verificamos que os mesmos não percebiam a necessidade de uma tecnologia alternativa ao dizer: "não temos problema tecnológico, pois nossas máquinas são de última geração" ou ainda "nosso problema é a falta de maquinário 
novo, pois o nosso está muito defasado".

Poderíamos especular - ao menos por enquanto - que os trabalhadores de FRs não percebem a natureza sócio-política da construção da tecnologia. Ao não observarem que algumas tecnologias - que poderiam trazer mais benefícios a eles - ainda não existem ou ficaram cristalizadas ao longo do caminho de seleção tecnológica, estes trabalhadores passam a crer que só há uma tecnologia disponível para uso no chão de fábrica. Ou ainda, eles não percebem a natureza sócio-política da construção da tecnologia (NOBLE, 2000).

Em Novaes e Dagnino (2004), evidenciamos que há um Fetiche que obscurece o caráter relacional da tecnologia (NOBLE, 1984; FEENBERG, 1999; MÉSZÁROS, 2002). Somente vemos aquilo que está na moda, uma suposta mudança contínua, incessante da tecnologia, e o avanço inexorável, sempre "benéfico". A tecnologia nos é apresentada no dia-a-dia como em plena evolução, onde todos os países devem aderir a "modernidade", como se esta fosse um bonde de via única. No entanto, nos esquecemos daquilo que não está mudando, isto é, das relações de dominação e as formas de controle que continuam a moldar a sociedade e a tecnologia (NOBLE, 1984 e 2001).

Mesmo verificando que existem progressos no que se refere a manutenção, reparação, pequenas adaptações do maquinário e aumento do conhecimento do processo produtivo, ainda se verifica uma imensa quantidade de trabalho alienante, repetitivo e totalmente desprovido de conteúdo[23]. Em linhas gerais, pode-se dizer que as FRs argentinas e uruguaias se encontram, em sua grande maioria, nas modalidades 2 ou 3.

Por último, mas não menos importante, deveremos destacar como inovações sociais na Argentina e no Uruguai, desde a permissão para se tomar mate no chão de fábrica, espaços de recreação, criação de cursos de pintura, escultura, aulas de segundo grau dentro das fábricas, outros eventos culturais como a ida de uma pianista famosa que emocionou muitos trabalhadores, e até mesmo a criação de creches dentro das fábricas. Se para a Economia Política existe apenas a categoria trabalho e não a de trabalhador, nas FRs a ótica é facilitar ao máximo a vida do trabalhador em seu ambiente de trabalho.

Uma ressalva deve ser feita. Alguns pesquisadores vêem nesta abertura das FRs ao público uma tática, um marquetingue político, alheio aos trabalhadores, onde esses não fazem parte da cultura.

\section{Considerações finais}

"Estamos trabalhando contra o desemprego. É uma alternativa concreta que os trabalhadores enfrentam frente a falta de resposta do Governo e dos patrões"

"Isso é o que queremos construir, empresas com todos os trabalhadores possíveis" 
Quando se pergunta qual é o objetivo último dos trabalhadores e presidentes dos movimentos sociais, dizem que, por enquanto, uma fábrica que é recuperada pelos trabalhadores é apenas uma experiência de "contenção social".

Funcionando muito mais por pragmatismo do que por ideologia socialista, os gritos mais à esquerda das FRs que ecoam na Argentina e Uruguai clamam pelo emprego, pela libertação nacional e o não pagamento da dívida externa. Talvez simbolizando muito bem o que serão os movimentos sociais na primeira metade do século $X X$, verifica-se a ausência de um projeto social radical que tenha um norte "para além do capital" (MÉSZÁROS, 2002).

Raras vezes se menciona que estas podem ser extremamente úteis ao sistema capitalista, ou ainda, ser "colonizadas", nas palavras de Heller (2004). Longe de causar um abalo sísmico no sistema, aquilo que teoricamente se constituiria como uma alternativa radical, apontada por alguns como os germes do socialismo no oceano capitalista, pode acabar se tornando uma via de "controle social dos pobres" onde as classes dominantes mantêm o domínio do "núcleo duro" da economia[24]. Se é verdade que toda empresa que "cierra, debese ocuparla e ponerla a producir", o que fazem os trabalhadores quando as fábricas não fecham?[25]

Tendo em vista os processos de AST, ou o calor do momento ainda não permitiu uma avaliação mais significativa dos processos engendrados ou tudo leva a crer que há uma tendência ao congelamento em apenas um aspecto da autogestão: a decisão compartilhada dos problemas vitais da empresa. Mesmo assim, deve-se lembrar que muitas empresas ou são dirigidas pelo movimento e/ou os trabalhadores ainda não participam plenamente das decisões vitais das fábricas.

Em grande medida devido ao fetiche da tecnologia ou a visão de que as forças produtivas avançam inexoravelmente, tanto a academia como os trabalhadores se mostram como anti-ludditas, mencionando apenas a apropriação das forças produtivas, ou no máximo, a ampliação dos conhecimentos das fases de produção pelos trabalhadores e algumas modificações na organização do processo de trabalho.

\section{Agradecimentos}

Agradeço todo apoio, críticas e sugestões dos amigos Jose Abelli, Julieta Caffaratti, Javier Ghibaudi, Mariana Movicz e os colegas do Centro Cultural desde el Pie; Silvana, Guillermina, Natália Bauni, Carina Balladares (pelos ensinamentos em antropologia), Antônio Cruz (seguramente este trabalho não seria o mesmo sem sua ajuda), Luiz Gaiger, Felipe Silva e João Henrique Almeida. Agradeço também todos os ensinamentos dos 
professores Gabriel Fajn, Andrés Ruggeri, Jorge Cugliota, Hugo Trinchero, Alberto Bialakowsky, Hector Palomino, Alejandro La Fleur, Fernando Torres, Juan Pablo Marti e Sara Rietti.

Aos colegas do mestrado em Política e Gestão da Ciência e Tecnologia e da graduação em Sociologia da UBA, aos colegas da Universidade de Quilmes, especialmente Alberto, Carla, Santiago, Juan Pablo, Leopoldo, Dario Codner, Leo Vacarezza, e Pablo Kreimer, por todo apoio prestado.

Aos meus colegas de mestrado da Unicamp, especialmente Cássio e Claudiana.

Aos trabalhadores das Fábricas Impa, Funsa, Coopdi, Nibo Plast, Constituyentes e Brukman pelos valiosos ensinamentos, por todo entusiasmo durante meus questionamentos e pela esperança que têm de uma vida melhor.

\section{Referências Bibliográficas:}

ASSENBURG, B. "A autogestão no caminho da heteronomia à autonomia: ponderações sobre experiências autogestionárias em cooperativas de calçados”. São Leopoldo:

Unisinos, III Encontro de Investigadores Latino-americanos de cooperativismo, 2004 (CD-Rom).

BERTULLO, J. et al. El cooperativismo en Uruguay. Montevideo: Unidad de Estudios Cooperativos, Universidad de la República, 2003.

BIALAKOWSKY, A. et al. "Cooperación y conflicto en las nuevas formas de autogestión de los trabajadores". Arequipa (Peru): XXIV Congreso da Alas, 2003.

BIJKER, W. E. Of Bicycles, Bakelites, and Bulbs. Toward a Theory of Sociotechnical Change. Massachusetts, MIT Press, 1995.

BRAVERMAN, H. Trabalho e capital monopolista. Rio de Janeiro: Ed. Guanabara, 1987.

BURAWOY, M. The politics of production. London - New York: Verso. 3ª edição, 1990.

CAFFARATTI, J. "Empresas recuperadas - Pauny (ex Zanello): estudio de caso". São Leopoldo, Unisinos: III Encontro de investigadores latino-americanos de cooperativismo, 2004.

CRUZ, A. "O Mar e a Terra da Economia Solidária". Curitiba: XXIX Encontro Nacional da ANPEC, 2002 (Obtido em www.itcp.unicamp.br em maio de 2004). 
DAGNINO, R. Enfoques sobre a relação Ciência, Tecnologia e Sociedade: Neutralidade e Determinismo. In: Organização dos Estados Ibero-americanos para a Educação, a ciência e a cultura, Sala de Lectura CTS+l de la OEI. Obtido em http://www.campus-oei.org/salactsi/index.html, 2002.

DAGNINO, R. Um Debate sobre a Tecnociência: neutralidade da ciência e determinismo tecnológico. Campinas: Livro Inédito, impresso, 2005.

DAGNINO, R.; BRANDÃO, F.C. e NOVAES, H.T. "Sobre o marco analítico conceitual da tecnologia social". In: Tecnologia Social - uma estratégia para o desenvolvimento. Rio de Janeiro, Fundação Banco do Brasil, 2004, p.15 a 64. (Pode ser obtido em www.redetecnologiasocial.net).

FAJN, G. et al. Fábricas y empresas recuperadas - protesta social, autogestión y rupturas en la subjetividad. Buenos Aires: Ediciones del Insituto Movilizador de Fondos Cooperativos, 2003.

FARIA, M. S. "...Se a coisa é por aí, que autogestão é essa ...?” Um estudo da experiência "autogestionária" dos trabalhadores da Makerli Calçados. Dissertação (Mestrado em Administração - Programa de Pós-Graduação em Administração). Florianópolis: Universidade Federal de Santa Catarina, 1997.

FEENBERG, A. A filosofia da tecnologia numa encruzilhada. 1999 [Tradução de Newton Ramos-de-Oliveira] (http://www-rohan.sdsu.edu/faculty/feenberg). Retirado em março de 2003.

FEENBERG, A. Transforming technology. Oxford University Press, 2002.

GHIBAUDI, J. "Crisis, Acción colectiva y Territorio: el fenómeno de las fábricas 'recuperadas' en el área metropolitana de Buenos Aires a partir de tres casos de estúdio". Rio de Janeiro, UFRJ: IX Semana de Planejamento Urbano e Regional IPPUR, Setembro de 2003.

HELLER, P. Fábricas Ocupadas. Buenos Aires: Ediciones Rumbos, 2004.

HERRERA, A. et al. Las nuevas tecnologias y el futuro de la America Latina. México, Siglo XXI editores, 1994.

HOBSBAWM, E. "Os destruidores de Máquinas". In: HOBSBAWM, E. Os trabalhadores estudos sobre a história do operariado. Rio de Janeiro: Paz e Terra, 1981.

HOLZMANN, L. "Gestão Cooperativa: limites e obstáculos à participação democrática". In: SINGER, P. e SOUZA, A. (orgs) A Economia Solidária no Brasil. São Paulo: Contexto, 
2000.

Informe de relevamiento entre empresas recuperadas por los trabajadores. Universidad de Buenos Aires, Facultad de Filosofía y Letras. www.mnerweb.com.ar/documentos.html, 2004.

KLEIN, N. Prefácio do Livro de MAGNANI, E. El cambio Silencioso - empresas y fábricas recuperadas por los trabajadores en la Argentina. Buenos Aires: Prometeo Libros, 2003.

LIMA Filho, P.A. Argentina, um futuro em ruínas. A pauperização e os sonhos dos trabalhadores: eles sonham com a volta ao passado?. Campinas, mimeo, 2002. Livro Inédito.

MAGNANI, E. El cambio silencioso - empresas y fábricas recuperadas por los trabajadores en la Argentina. Buenos Aires: Prometeo Libros, 2003.

MARTI, J.P. et al. "Empresas recuperadas mediante la modalidad de cooperativas de trabajo: apuntes para la comprensión de su surgimiento". São Leopoldo, Unisinos: 3o

Encontro de investigadores latino-americanos de cooperativismo, 2004.

MARX, K. "Instrucción sobre diversos problemas a los delegados del Consejo Central Provisional (1866)". C. Marx \& F. Engels, Obras Escogidas (en três tomos), tomo II, Editorial Progreso, Moscú. (www.marxists.org) Retirado em novembro de 2004.

MARX, K. Miséria da Filosofia. São Paulo: Livraria exposição do livro, 1966.

MÉSZÁROS, I. Para além do capital. São Paulo: Boitempo, 2002.

MURUA, E. "Charla en el $2^{\circ}$ Congreso Nacional de Sociologia". Buenos Aires, II Congresso Nacional de Sociologia, UBA, 2004.

NOBLE, D. Forces of production. New York: Alfred Knopf, 1984.

NOBLE, D. Una visión diferente del progreso - En defensa del luddismo. Barcelona: Alikornio, 2000.

NOBLE, D. La loucura de la automatización. Barcelona: Alikornio, 2001.

NOVAES, H.T. Os Simões Bacamarte da Economia Solidária. Campinas: Incubadora Tecnológica de Cooperativas Populares, 2004a (Pode ser obtido em www.itcp.unicamp.br ou em http://eiffel.dcc.ufla.br/abpes/).

NOVAES, H.T. Idéias de Canário e 0 Alienista: debatendo as faces da alienação em cooperativas de trabalhadores a partir de Machado de Assis. Campinas: mimeo, 2005b. 
NOVAES, H.T. Para além da apropriação dos meios de produção? O processo de adequação sócio-técnica em fábricas recuperadas. Dissertação de Mestrado. Departamento de Política Científica e Tecnológica. Campinas: Unicamp, 2005c. (Pode ser obtida em www.unicamp.br/bc).

NOVAES, H.T. e DAGNINO, R. "O Fetiche da Tecnologia". Marília: Ed. Unesp, Revista Organizações \& Democracia, número 2, vol. 5, 2004.

NOVAES, H.T. e DAGNINO, R. "Tecnologia para quê? Que tipo de Tecnologia? Tecnologia para quem?: uma incursão na obra de David Noble". Campinas: X Encontro Nacional de Economia Política, maio de 2005. CD-Rom.

NOVAES, H., ASSIS, U. e DAGNINO, R. "Mapeando mudanças em empresas recuperadas sob a óptica do conceito de Adequação Sócio-Técnica". 2 Encontro Internacional de Economia Solidária: São Paulo: Usp, junho de 2004 (O artigo completo pode ser obtido em www.itcp.unicamp.br).

PALOMINO, H. et al. "El movimiento de trabajadores de empresas recuperadas". Revista Sociedad n-20-21. Buenos Aires, Facultad de Ciencias Sociales, 2003.

RAPOPORT, M y Colaboradores. La Historia política, econômica y social de la Argentina (1880 - 2000). Buenos Aires, Ediciones Macchi, 2000.

SINGER, P. I. Uma utopia militante: repensando o socialismo. Rio de Janeiro: Vozes, 1998.

VARSAVSKY, O. Estilos tecnológicos - propuestas para la selecion de tecnologías bajo racionalidad socialista. Buenos Aires, Ediciones Periferia, 1974.

VIEITEZ, C. e DAL RI, N. Trabalho associado. Rio de Janeiro, DP\&A, 2001.

Filme: DANÇANDO NO ESCURO. Diretor:Lars Von Trier.

Entrevistas: Bloz (Impa), Roberto, Daniel e Wilson (Funsa), Alícia Paiva e toda equipe da Coopdi, Hugo Beloso e trabalhadores da Nibo Plast, Pascoal (Constituyentes), Coca e Santiago (Brukman).

[1] Este artigo foi publicado na Revista de Ciências Sociais da Unisinos, 2005, vol. 42, número 166, p. 800830. (São Leopoldo-RS).

[2] Economista (Unesp-Araraquara-SP) e Mestre em Política Científica e Tecnológica na Unicamp (2005). Mebro do GAPI e da ABPES. Bolsista do Convênio CAPES/UBA de setembro a novembro de 2004 e da FAPESP de setembro de 2003 a julho de 2005. Correio eletrônico: hetanov@ige.unicamp.br. Telefone (19) 91055626. 
[3] Para saber sobre os demais resultados da pesquisa, inclusive no Brasil, ver Novaes (2005c).

[4] Para ficar somente com um exemplo de interpretação apressada, citamos uma canadense que esteve por aqui: "Em 1812, bandas de tejedores y urdidores británicos allanaron las fábricas textiles y destrozaron las máquinas industrialles con sus martillos. Segun los ludditas, los nuevos telares mecanizados habían eliminado miles de trabajos, fragmentando comunidades y merecían ser destruídas. El gobierno británico discrepó y llamó a un batallon de 14.000 soldados, que brutalmente reprimió la revuelta de los trabajadores y protegió las máquinas". E continua "Adelantémonos dos siglos a otra fábrica textil, ésta em Buenos Aires. En lá fábrica Brukman, que ha estado produciendo trajes para hombre durante 50 años, es el allanamiento policíaco el que destroza las máquinas de coser y a los 58 trabajadores que arriesgan sus vidas para protegerlas" (Klein -Prólogo ao Livro de Magnani, 2003, p.13). Esta passagem que nos levou a pensar neste formato de artigo.

\section{[5] Revolta camponesa na França em 1358.}

[6] A rápida derrota do luddismo levou a uma crença generalizada de que a quebra de máquinas nunca era bem sucedida.

[7] Para saber mais sobre o pensamento do historiador da tecnologia David Noble, ver Novaes e Dagnino (2005).

[8] Isso não significa dizer que o capital se autodestrua.

[9] Para saber mais sobre os laços inter cooperativas e entre cooperativas e a "sociedade", especialmente as assembléias de bairro, ver Ghibaudi (2002), Fajn et al. (2003) e Magnani (2003).

[10] As palavras são do professor Gabriel Fajn.

[11] É preciso ressaltar que muitas dessas fábricas operam hoje com $1 / 5$ dos trabalhadores nos tempos gloriosos. Metade das empresas investigadas por Fajn et al. (2003) tem menos de 30 empregados e 25\% mais de 70. Na Argentina, as cooperativas que surgem de falência ou abandono abrangem campos que não encontramos no Brasil: que Clínicas de exame, Hospitais, supermercados, escolas e somam um total de 180 fábricas (de um total aproximado de 4000 falências) e 12000 trabalhadores. No Uruguai, temos também um forte cooperativismo "de esquerda" para a construção "de viviendas" e as fábricas recuperadas devem girar em torno de 20. Ver Bertullo et al. (2003).

[12] Para saber mais sobre o caso brasileiro, ver Faria (1997), Singer (1998), Vieitez e Dal Ri (2001), Cruz (2003), e Novaes (2005c).

[13] Heller (2004) também ressalta que houve "vandalismo" por parte dos trabalhadores.

[14] A guarda das fábricas causou muito estresse e cansaço nos trabalhadores. Ver, por exemplo, Magnani (2003, p.151).

[15] Varsavsky (1974) e Dagnino (2002) propõem não só uma radical mudança da forma de fazer pesquisa, como também de se dar aula.

[16] Isso não quer dizer que a mentalidade de receber um salário sem se importar com o andamento da fábrica tenha se extinguido. No entanto, verifica-se em muitas fábricas um aumento significativo da produtividade e um sentimento de propriedade sobre a fábrica.

[17] No seio das FRs, mostra-se claramente um sentimento de que as fábricas são bem públicos ou bens sociais, estando a frente de qualquer direito à "propriedade privada" que o antigo dono reivindica. Ver, por exemplo, (MAGNANI, 2003, p.66).

[18] Para ver a crítica ao postulado "para igual trabalho igual salário", pode-se ler o Prefácio de "A miséria da filosofia" feito por Engels (1966 apud MARX, 1966) e as críticas de Marx (1966) aos "ricardianos de esquerda".

[19] Na pesquisa de Fajn (2003), constata-se que 70\% das fábricas optaram pela igualação dos sueldos (salários).

[20] Isso não significa dizer que a remuneração atual dos trabalhadores latinos permite a satisfação das 
necessidades humanas. Seguramente deverá haver um aumento significativo dos salários.

[21] Caberia investigar como estão se constituindo as relações nas poucas fábricas onde ficaram os quadros hierárquicos e compará-las com aquelas onde somente há trabalhadores.

[22] Esse problema também foi constatado em muitas cooperativas terceirizadas produtoras de calçados e vestuário no Brasil. Ver, por exemplo, Assenburg (2004).

[23] Verificamos que muitos trabalhadores recorrem a Música para libertar-se da atividade de trabalho repetitiva. Aqui, cabe um paralelo com o Filme Dançando no Escuro (Lars Von Trier), onde a atriz-cantora Bjork vê na música um ato de devaneio frente ao trabalho aporrinhante.

[24] Ver, por exemplo, o caso da Argélia em Burawoy (1990). Para Marx (1866), o movimento cooperativo, "limitado a las formas enanas, las únicas que pueden crear con sus propios esfuerzos los esclavos individuales del trabajo asalariado, jamás podrá transformar la sociedad capitalista. A fin de convertir la producción social en un sistema armónico y vasto de trabajo cooperativo son indispensables cambios sociales generales, cambios de las condiciones generales de la sociedad, que sólo pueden lograrse mediante el paso de las fuerzas organizadas de la sociedad, es decir, del poder político, de manos de los capitalistas y propietarios de tierras a manos de los productores mismos". Já Marx (1994) destaca os fatores que independem da conquista do poder político, tais como a alienação do produto do trabalho, do processo de trabalho, de si e da civilização humana (NOVAES, 2004b).

[25] Numa pesquisa realizada no fim de 2004 junto a trabalhadores de FRs, perguntaram se era legítimo ocupar fábricas que não fecharam: $90 \%$ dos trabalhadores responderam que não.

Resumo: O artigo aborda o processo de Adequação Sócio-Técnica nas Fábricas Recuperadas argentinas e uruguaias. Sabendo que muitas fábricas faliram ou foram abandonadas por seus antigos donos no fim do século XX e início do século XXI, os trabalhadores optaram por recuperar seus postos de trabalho e colocar em marcha novamente a produção. Para atingir seu objetivo - debater os entraves e as possibilidades de construção da autogestão em fábricas de trabalhadores - coloca-se em cena o movimento luddita e procurase desmistificar algumas interpretações apressadas. Além disso, tivemos na Argentina uma espécie de luddismo às avessas, já que muitos patrões destruíram máquinas para impedir o controle operário. Verificouse que as inovações argentinas e uruguaias referem-se basicamente a manutenção e ampliação do conhecimento fabril, não só do processo produtivo, mas também em alguns aspectos administrativos. Muitas fábricas optaram pela repartição igualitária do salário. Encontramos também pequenas modificações no maquinário, na divisão do trabalho e o desenvolvimento de novos produtos. Dentre as inovações sociais, destacam-se a criação de espaços para a promoção de eventos culturais e para a adaptação da fábrica aos interesses dos trabalhadores.

Palavras-chave: Fábricas Recuperadas, Ludditas, Autogestão, forças produtivas, cooperativas

\section{Title: When the bosses destroy machines: the debate around the productive forces in argentineans and uruguayans recovered factories}

Abstract: The article approaches the Socio-Technical Adequation Process in the argentineans and uruguayans Recovered Factories. Facing the fact that a large number of factories failed or were abandoned for their old owners at the end of the century XX and beginning of the century XXI, workers opted to recover their jobs and reestablish production. To achieve our objective - debating the impediments and the possibilities of constructing of the self-management in workers' factories - we introduce the luddish movement and try to demystify some mistaken interpretations. Besides, in Argentina, we have a inside out kind of luddish moviment, since many bosses destroyed machines to block labor control. It was verified that the argentinean and uruguayan innovations tend to the maintenance and enlargement of the industrial knowledge basically, not only of the productive process perspective, but also in some administrative aspects. Many factories opted for the equalitarian partition of the wage. It also can be found small modifications in the machines, in the division of the work and the development of new products. Among the social innovations, we emphasize the creation of spaces for the promotion of cultural events and for the adaptation of the factory to the workers' interests.

Key-words: Recovered Factories, Luddism, Self-management, forces of production, cooperatives. 
file://C:LDocuments and Settings\AdministradorlMeus documentos\Minhas Webs\NED... 4/9/2008 